\title{
Efficacy of Prolonged Treatment With Pegylated Interferon (Peg-IFN) and Ribavirin in Thalassemic Patients With Hepatitis C Who Relapsed After Previous Peg-IFN-Based Therapy
}

\author{
Saleh Sandoughdaran ${ }^{1}$; Seyed Moayed Alavian ${ }^{1,2}$; Heidar Sharafi ${ }^{1,2}$; Bita Behnava ${ }^{1,2}$; Shima \\ Salimi ${ }^{1,2} ;$ Leila Mehrnoush $^{1,2} ;$ Pegah Karimi Elizee $^{2}$; Maryam Keshvari ${ }^{2,3,{ }^{*}}$ \\ ${ }_{1}^{1}$ Baqiyatallah Research Center for Gastroenterology and Liver Diseases, Baqiyatallah University of Medical Sciences, Tehran, IR Iran \\ 2 Middle East Liver Diseases (MELD) Center, Tehran, IR Iran \\ 3 Blood Transfusion Research Center, High Institute for Research and Education in Transfusion Medicine, Tehran, IR Iran \\ *Corresponding Author: Maryam Keshvari, Blood Transfusion Research Center, High Institute for Research and Education in Transfusion Medicine, Hemmat Exp Way, Next to Milad \\ Tower, Tehran, IR Iran. Tel: +98-2188601501, Fax: +98-2166900386, E-mail: m.keshvari@ibto.ir
}

Received: September 16, 2014; Revised: November 21, 2014; Accepted: December 22, 2014

\begin{abstract}
Background: Most thalassemic patients with chronic hepatitis C virus (HCV) infection do not respond to therapy with pegylated interferon (Peg-IFN) plus ribavirin (RBV) due to hepatic siderosis and RBV dose reduction caused by RBV-induced anemia.

Objectives: In the present study, we recruited HCV genotype 1-infected thalassemic patients who had relapsed after a 48-week treatment with Peg-IFN plus RBV in order to evaluate the efficacy of a 72-week regimen of Peg-IFN plus RBV.

Patients and Methods: In this retrospective study, 23 thalassemic patients with HCV genotype 1 infection who had prior relapse after treatment with Peg-IFN and RBV for 48 weeks were consecutively enrolled in this study for evaluation of the efficacy of a 72-week treatment regimen.

Results: For the 21 included cases, mean age was 29.7 years; $81 \%$ were men and $28.6 \%$ had cirrhosis. At the end of the treatment, nine (42.9\%) patients had an undetectable level of HCV RNA in their sera. However, six months after treatment completion four of these patients relapsed and a sustained virological response (SVR) was found in five (23.8\%) patients. Undetectable HCV RNA level at week $4(\mathrm{P}=0.03)$ and undetectable HCV RNA level at week $12(\mathrm{P}<0.01)$ were found to be predictors of SVR. There was an average $47.9 \%$ increase in blood transfusion during therapy and treatment was discontinued for $12(57.1 \%)$ patients prematurely.

Conclusions: The present study suggests that thalassemic patients with chronic hepatitis $C$ genotype 1 infection who did not achieve SVR after a course of therapy with Peg-IFN and RBV may benefit from being retreated with a 72-week regimen.
\end{abstract}

Keywords:Hepatitis C; peginterferon alfa-2a; Ribavirin; Thalassemia

\section{Background}

It is estimated that $130-150$ million people are infected with hepatitis $\mathrm{C}$ virus (HCV) worldwide and more than 350000 people die of HCV-related conditions including cirrhosis and liver cancer annually (1). Thalassemia is an important healthcare problem with approximately 18000 transfusion-dependent thalassemic patients in Iran (2). Patients with thalassemia major are at higher risk for acquisition of hepatitis $\mathrm{C}$ due to blood transfusion. Previous studies in Iran have demonstrated the prevalence of HCV in multiple-transfused thalassemic patients to be $8 \%-31 \%$ (3-5). Most of these HCV-infected patients started receiving blood before the introduction of the donor screening program for HCV in 1996 (6).

Treatment of chronic HCV infection in thalassemic patients is complicated by hepatic siderosis and ribavirin (RBV) dose reduction caused by RBV-induced anemia. Clinical trials investigating the efficacy of pegylated interferon (Peg-IFN) and RBV in HCV-infected thalassemic patients demonstrated overall sustained virological response (SVR) rates ranging from $50 \%$ to $62 \%(7,8)$. Moreover, the iron overload worsens the outcome of liver disease following multiple transfusion, often reducing the chance of achieving SVR. The majority of thalassemic patients who fail to achieve SVR following the first course of HCV treatment, are at risk of developing progressive liver disease in the long-term such as cirrhosis and/or hepatocellular carcinoma (HCC) with the possibility of needing liver transplantation.

The currently recommended treatment regimen for patients with HCV genotype 1 infection is Peg-IFN in combination with RBV for 48 weeks. In contrast to patients without inherent hemoglobinopathy, RBV can induce lifethreatening anemia in thalassemic patients and thus it is generally contraindicated in these patients. However, a recent study showed that adult thalassemic patients with HCV infection can be treated successfully with RBV (8). 
Several clinical trials have shown that extending therapy to 72 weeks may increase SVR in patients with HCV genotype 1 infection who have not responded to a previous course of treatment (9-11). However, to date there are no published studies on the use of extended Peg-IFN-based therapy in $\mathrm{HCV}$-infected thalassemic patients.

\section{Objectives}

In the present study, we recruited HCV genotype 1-infected thalassemic patients who had relapsed after a 48-week treatment with Peg-IFN plus RBV to evaluate the efficacy of a 72-week regimen of Peg-IFN plus RBV.

\section{Patients and Methods}

\subsection{Patient Selection}

In this retrospective study, 23 consecutive thalassemic patients with HCV genotype 1 infection who had previously relapsed after treatment with Peg-IFN and RBV for 48 weeks and still had detectable HCV RNA (> $50 \mathrm{IU} / \mathrm{mL}$ ) in their serum were enrolled and evaluated at the Clinical Department of Baqiyatallah Research Center for Gastroenterology and Liver Diseases (BRCGL) (Tehran, Iran) from the year 2011 to 2013. Patients were excluded if they had any of the following criteria: younger than 18 years of age, neutropenia (absolute neutrophil count $<1.0 \times 10^{9} / \mathrm{L}$ ), thrombocytopenia $\left(<60 \times 10^{9} / \mathrm{L}\right)$, infection with hepatitis $B$ virus or HIV, decompensated liver disease, serum creatinine greater than 1.5 times of the upper limit of normal and major psychiatric illness. Two patients received PegIFN alpha-2a (Pegasys, Roche, Basel, Switzerland) at a dose of $180 \mu \mathrm{g} /$ week and the remaining were treated with PegIFN alpha-2b (PegIntron, Schering-Plough, Las Piedras, Puerto Rico, USA) at a dose of $1.5 \mu \mathrm{g} / \mathrm{kg} /$ week plus RBV (Copegus, Roche or Rebetol, Schering-Plough) 600-800 $\mathrm{mg} /$ day according to the patient's hemoglobin level for 72 weeks. Patients with a hemoglobin level of 8-10 g/dL received $600 \mathrm{mg} \mathrm{RBV}$, whereas those with hemoglobin level of over $10 \mathrm{~g} / \mathrm{dL}$ received $800 \mathrm{mg}$ RBV. All patients underwent percutaneous liver biopsy. Each biopsy specimen was evaluated according to the modified Knodell score grading and staging system.

\subsection{Assessment of Safety}

Patients were followed for 24 weeks after the end of treatment. Routine visits were scheduled every 4 weeks for evaluation of adverse events and probable dose adjustments. Alanine aminotransferase (ALT) level and complete blood count were checked at every visit and thyroid function tests were performed every 12 weeks. The HCV RNA level was measured before treatment and at weeks 4, 12, 24, 48 and 72 after starting treatment and also 24 weeks after the end of the treatment course. The HCV RNA level was determined using $\operatorname{COBAS}^{\circledR}{ }^{\circledR} \operatorname{TaqMan}^{\circledR}$ HCV Test v2.0 (Roche Diagnostics) according to the manufacturer's instructions with a detection limit of $10 \mathrm{IU} / \mathrm{mL}$.
Written consent was obtained from all patients. The study protocol was approved by the Baqiyatallah University of Medical Sciences Review Board and was conducted according to the guidelines of the Declaration of Helsinki.

\subsection{Assessment of Efficacy}

A rapid virological response (RVR) was defined as undetectable serum HCV RNA level at week 4 of treatment. Early virological response (EVR) was defined as undetectable HCV RNA level at week 12 (complete EVR) or at least a 2 log decrease in HCV RNA level (partial EVR). An end of treatment response (ETR) was defined as undetectable HCV RNA level at the end of treatment. The outcome of the treatment was achievement of a sustained virological response (SVR), which was defined as undetectable HCV RNA level 24 weeks after treatment completion. Relapse was defined as response to treatment with undetectable HCV RNA at the end of treatment and reappearance of HCV RNA within 24 weeks after treatment termination. Patients with an insufficient virological response at week 12 (a decrease of $<2 \log 10 \mathrm{IU} / \mathrm{mL}$ from the baseline HCV RNA level) and a detectable HCV RNA level at week 24 of treatment were considered as having treatment failure and were withdrawn from the treatment.

\subsection{Statistical Analysis}

The data was analyzed using SPSS software (version 20.0). The independent t-test with bootstrap resampling was used for analysis of continuous variables. Fisher's exact test and Monte Carlo simulation were used for comparison of group frequencies. $\mathrm{P} \leq 0.05$ were considered significant.

\section{Results}

A total of 23 thalassemic patients were enrolled in this study and two of them were excluded due to having the liver decompensation criteria. The demographic and other characteristics of the patients are shown in Table 1. Overall, 17 (81.1\%) patients were male and 10 (47.6\%) patients had a high baseline HCV RNA level (> $800000 \mathrm{IU} /$ $\mathrm{mL}$ ), with a mean HCV RNA level of $1363560 \mathrm{IU} / \mathrm{mL}$. Body mass index (BMI) was $21.4 \pm 3.1 \mathrm{~kg} / \mathrm{m}^{2}$ among the studied patients. Five (23.8\%) patients carried the rs12979860 CC genotype and 16 (76.2\%) patients carried the rs12979860 CT/TT genotypes. Liver fibrosis was mild to moderate in 15 (71.4\%) patients, whereas 6 patients (28.6\%) had cirrhosis. At the end of treatment, nine (42.9\%) patients had an undetectable HCV RNA. However, six months after treatment completion four cases relapsed and SVR was found in five (23.8\%) patients. Early virological response (EVR) was obtained in seven (33.3\%) patients. Of those who achieved EVR, five patients achieved SVR as well. The achievement of EVR provided a negative predictive value of $100 \%$. The positive predictive value for achievement SVR was similar between patients with RVR (75\%) and EVR (71\%). Four (19.0\%) patients relapsed following termination of treatment. In the total sample, treatment was 
Sandoughdaran S et al.

Table 1. Baseline Demographic, Virological, and Histological Features of Patients $(\mathrm{n}=21)^{\mathrm{a}, \mathrm{b}}$

\begin{tabular}{|c|c|}
\hline Characteristics & Data \\
\hline Gender, Male/Female & $17(81) / 4(19)$ \\
\hline Age, $y$ & $29.7 \pm 5.9$ \\
\hline BMI, $\mathrm{kg} / \mathrm{m}^{2}$ & $21.4 \pm 3.1$ \\
\hline Baseline ALT, IU/L & $53.6 \pm 36.3$ \\
\hline Serum ferritin, $\mathbf{n g} / \mathbf{m L}$ & $831.8 \pm 599.4$ \\
\hline \multicolumn{2}{|l|}{ rs12979860 } \\
\hline $\mathrm{CC}$ & $5(23.8)$ \\
\hline Non-CC & $16(76.2)$ \\
\hline \multicolumn{2}{|l|}{ Histological findings } \\
\hline Fibrosis stage $0-2$ & $11(52.4)$ \\
\hline Fibrosis stage 3-4 & $4(19.0)$ \\
\hline Fibrosis stage 5-6 & $6(28.6)$ \\
\hline \multicolumn{2}{|l|}{ Serum HCV RNA, IU/mL } \\
\hline$<800,000$ & $11(52.4)$ \\
\hline$\geq 800,000$ & $10(47.6)$ \\
\hline
\end{tabular}

Table 2. Adverse Events of Treatment in Enrolled Patients ( $\mathrm{n}=$ 21) ${ }^{\mathrm{a}}$

\begin{tabular}{lc}
\hline Adverse Events & Data \\
\hline Neutropenia & $1(4.8)$ \\
\hline Thrombocytopenia & $1(4.8)$ \\
\hline Headache & $15(71.4)$ \\
\hline Insomnia & $9(42.9)$ \\
\hline Depression & $5(23.8)$ \\
\hline Weight loss & $5(23.8)$ \\
\hline Myalgia & $18(85.7)$ \\
Nausea & $5(23.8)$ \\
Diarrhea & $5(23.8)$ \\
Cough & $7(33.3)$ \\
\hline Hair fall & $19(90.5)$ \\
Pruritus & $4(19)$ \\
\hline Fever & $18(85.7)$ \\
\hline a Data are presented as No. (\%).
\end{tabular}

${ }^{a}$ Data are presented as No. (\%).

discontinued in 13 (61.9\%) patients prematurely. Treatment was withdrawn prematurely in 12 patients due to nonresponse and in one patient because of severe proteinuria.

The frequent reported adverse events by the patients were hair fall (90.5\%), fever (85.7\%), musculoskeletal pain (85.7\%) and headache (71.4\%) (Table 2). Of the 21 patients, one developed thrombocytopenia and one patient developed neutropenia, which led to Peg-IFN dose reduction and G-CSF administration. There was an average $47.9 \%$ increase in blood transfusion during therapy.

Efficacy data for each group of parameters were analyzed separately in the bivariate analysis of possible predictors versus SVR and are presented in Table 3. Patients without SVR tended to have higher baseline HCV RNA level compared to patients with SVR (6.18 vs. $5.67 \log 10 \mathrm{IU} / \mathrm{mL}, \mathrm{P}=$ $0.08)$, although this difference was not significant.
Table 3. Patients' Characteristics and On-treatment Response by Sustained Virological Response ${ }^{\mathrm{a}, \mathrm{b}}$

\begin{tabular}{|c|c|c|c|}
\hline Characteristics & $\operatorname{SVR}(-)(n=16)$ & $\operatorname{SVR}(+)(\mathbf{n}=5)$ & P Value \\
\hline Gender & & & $>0.99^{\mathrm{C}}$ \\
\hline Male & $13(81.3)$ & $4(80.0)$ & \\
\hline Female & $3(18.8)$ & $1(20.0)$ & \\
\hline Age, y & $29.3 \pm 5.4$ & $32.2 \pm 5.7$ & $0.32^{\mathrm{d}}$ \\
\hline BMI, $\mathrm{kg} / \mathrm{m}^{2}$ & $21.0 \pm 2.6$ & $21.8 \pm 5.1$ & $0.75^{\mathrm{d}}$ \\
\hline $\begin{array}{l}\text { Baseline ALT, } \\
\text { IU/L }\end{array}$ & $51.6 \pm 29.0$ & $50.0 \pm 36.8$ & $0.94^{\mathrm{d}}$ \\
\hline $\begin{array}{l}\text { Serum ferritin, } \\
\mathrm{ng} / \mathrm{mL}\end{array}$ & $850.3 \pm 647.1$ & $780.2 \pm 501.2$ & $0.85^{\mathrm{d}}$ \\
\hline rs12979860 & & & $>0.99^{c}$ \\
\hline $\mathrm{CC}$ & $4(25.0)$ & $1(20.0)$ & \\
\hline Non-CC & $12(75.0)$ & $4(80.0)$ & \\
\hline $\begin{array}{l}\text { Histological } \\
\text { findings }\end{array}$ & & & $>0.99^{C}$ \\
\hline $\begin{array}{l}\text { Fibrosis stage } \\
0-2\end{array}$ & $8(50.0)$ & $3(60.0)$ & \\
\hline $\begin{array}{l}\text { Fibrosis stage } \\
3-4\end{array}$ & $3(18.8)$ & $1(20.0)$ & \\
\hline $\begin{array}{l}\text { Fibrosis stage } \\
5-6\end{array}$ & $5(31.3)$ & $1(20.0)$ & \\
\hline $\begin{array}{l}\text { Serum HCV } \\
\text { RNA, IU/mL }\end{array}$ & & & $0.64^{\mathrm{C}}$ \\
\hline$<800,000$ & $8(50.0)$ & $3(60.0)$ & \\
\hline$\geq 800,000$ & $8(50.0)$ & $2(40.0)$ & \\
\hline EVR & $2(12.5)$ & $5(100)$ & $<0.01^{\mathrm{C}}$ \\
\hline RVR & $1(6.3)$ & $3(60.0)$ & $0.03^{\mathrm{C}}$ \\
\hline
\end{tabular}

a Abbreviations: ALT, alanine aminotransferase; BMI, body mass index; EVR, early virological response; RVR, rapid virological response; SVR, sustained virological response.

b Data are presented as mean \pm SD or No. (\%).

c Fisher exact test.

d t-test.

\section{Discussion}

To the best of our knowledge this is the first study that has determined SVR rate and predictors of response to prolonged chronic hepatitis $\mathrm{C}$ ( $\mathrm{CHC}$ ) treatment in thalassemic patients who relapsed after previous treatment with Peg-IFN and RBV. Transfusion-related infections especially chronic HCV infection increases the morbidity and mortality of thalassemic patients. Despite remarkable improvements in HCV treatment during the recent years, many thalassemic patients with chronic HCV infection still do not respond adequately to standard therapy. In our study, $23.8 \%$ of thalassemic patients with CHC achieved SVR when they were retreated with a prolonged course of Peg-IFN and RBV. This result is comparable to that described by Jacobson et al. (10) who found an SVR rate of 
$30 \%$ in non-thalassemic relapsers who were retreated with Peg-IFN alpha-2a and RBV. However, the obtained SVR rate in the present study was lower than the preliminary reports in naive, $\mathrm{HCV}$ genotype 1-infected thalassemic patients (62\%) (7). Given that the population of the present study had treatment-resistant characteristics, namely previous treatment failure, infection with HCV genotype 1 and significant fibrosis (55\% of patients had fibrosis stage $>2$ ), the obtained results regarding achievement of SVR is remarkable.

The duration of antiviral therapy is one of the important factors influencing treatment outcome, especially in HCV genotype 1-infected patients. Some studies have demonstrated that the SVR rate for patients who achieved partial EVR can be improved with longer treatment duration. Alavian et al. (12) in a meta-analysis showed that a 72-week therapy in HCV genotype 1-infected patients with Peg-IFN and RBV is significantly superior to the standard 48-week therapy in slow-responders. Pearlman et al. (13) conducted a study in which patients who achieved partial EVR on therapy with Peg-IFN and RBV were randomized to receive a 48- or 72-week therapy. Although there was no difference in the end-of-treatment response between the two groups, the SVR rates were significantly higher in patients who received the extended regimen ( $38 \% v s .18 \% ; \mathrm{P}=0.026)$. Ide et al. (14) showed that extending treatment to 72 weeks significantly increased SVR rate in patients with HCV genotype $1 \mathrm{~b}$ infection who had undetectable HCV RNA during weeks 16 to 24. In another study by Ferenci et al. (15) patients without RVR who achieved EVR were randomized to 48- or 72-week treatment groups. Extending therapy with Peg-IFN alfa-2a plus RBV to 72 weeks decreased the probability of relapse. Jensen et al. (11) also reported that in comparison with standard therapy, extending therapy to 72 weeks increased SVR rate from $9 \%$ to $16 \%$.

The present study showed that similar to other HCVtreated populations, 75\% of patients with RVR achieved SVR as well. It was shown that achieving RVR was dominant over all other variables at determining the likelihood of achieving SVR following Peg-IFN and RBV therapy (16). In this study, lack of EVR had a 100\% negative predictive value for achieving SVR. Thus, a decision to discontinue HCV therapy in HCV-infected thalassemic patients may be made early during the course of treatment, preventing unnecessary adverse events and costs.

It was shown that SVR was significantly higher in thalassemic patients with $\mathrm{CHC}$ who received peg-IFN and RBV combination therapy compared to patients who were treated with Peg-IFN monotherapy (8). Ribavirin-associated hemolysis is the most important side effect of combination therapy in thalassemic patients, which leads to a greater need for transfusion and increased risk of iron overload $(17,18)$. Overall, transfusion requirements rose by $47 \%$ in the present study which is consistent with the studies by Telfer et al. (19), Harmatz et al. (20) and Tabatabaei et al. (8), where the rate of blood transfusion was increased by $41 \%, 44 \%$ and $50 \%$, respectively.
Recent studies have identified single nucleotide polymorphisms (SNPs) rs12979860 and rs8099917 on chromosome 19q13.13 near the IFNL3 (IL28B) gene as markers associated with a higher SVR rate in HCV genotype 1-infected patients (21-24). Recently Di Marco et al. (25) showed that favorable genotypes of IL28B were independently associated with SVR in HCV-infected thalassemic patients who were treated with IFN. In contrast to their study, we found that rs12979860 SNP would not determine final treatment outcome in thalassemic patients with HCV genotype 1 infection. This contradiction might be due to the small sample size of our study.

Several direct acting antiviral agents (DAAs) have been developed which show potent activity against HCV and incrementally improve the rate of SVR even in patients with difficult-to-treat CHC. These drugs are safe with minimal side-effects. Given that the new drugs have high costs, they may not be affordable in low-income countries. As a result the conventional Peg-IFN and RBV dual therapy should be considered as a first-line regimen for $\mathrm{CHC}$ up to the next future in developing countries.

The main limitation of this study was its small sample size, which renders our findings less conclusive. The other limitation of the present study was its retrospective design which limited the quality of the obtained results.

In summary, the data of this study suggest that thalassemic patients with HCV genotype 1 infection, who did not achieve SVR after a course of therapy with Peg-IFN, may benefit from an extended 72-week therapy, even if they have apparently unfavorable predictors such as advanced hepatic fibrosis or cirrhosis. Further randomized controlled trials are required to evaluate the efficacy of Peg-IFN/RBV prolonged treatment in thalassemic patients with HCV infection.

\section{Acknowledgements}

We gratefully acknowledge the assistance of Middle East Liver Diseases (MELD) Center staff.

\section{Authors' Contributions}

Seyed Moayed Alavian, Bita Behnava and Maryam Keshvari designed the study; Seyed Moayed Alavian, Bita Behnava, Maryam Keshvari, Shima Salimi, Pegah Karimi Elizee and Leila Mehrnoush contributed to sample collection; Bita Behnava, Maryam Keshvari, Shima Salimi, Pegah Karimi Elizee and Leila Mehrnoush performed the study; Saleh Sandoughdaran and Heidar Sharafi analyzed the data; Saleh Sandoughdaran, Heidar Sharafi and Maryam Keshvari wrote the paper.

\section{References}

1. Singal AK, Singh A, Jaganmohan S, Guturu P, Mummadi R, Kuo YF, et al. Antiviral therapy reduces risk of hepatocellular carcinoma in patients with hepatitis C virus-related cirrhosis. Clin Gastroenterol Hepatol. 2010;8(2):192-9. 
2. Khodaei GH, Farbod N, Saeidi M. Frequency of Thalassemia in Iran and Khorasan Razavi. Int J Pediatr. 2013;1:45-50.

3. Abolghasemi H, Amid A, Zeinali S, Radfar MH, Eshghi P, Rahiminejad MS, et al. Thalassemia in Iran: epidemiology, prevention, and management. J Pediatr Hematol Oncol. 2007;29(4):233-8.

4. Ataei B, Hashemipour M, Kassaian N, Hassannejad R, Nokhodian $Z$, Adibi P. Prevalence of anti HCV infection in patients with Betathalassemia in isfahan-iran. Int J Prev Med. 2012;3(Suppl 1):S118-23.

5. Alavian S, Tabatabaei S, Lankarani K. Epidemiology of HCV Infection among Thalassemia Patients in Eastern Mediterranean Countries: a Quantitative Review of Literature. Iran Red Crescent Med J. 2010;12(4):365-76.

6. Alavian SM, Miri SM, Keshvari M, Elizee PK, Behnava B, Tabatabaei SV, et al. Distribution of hepatitis C virus genotype in Iranian multiply transfused patients with thalassemia. Transfusion. 2009;49(10):2195-9.

7. Inati A, Taher A, Ghorra S, Koussa S, Taha M, Aoun E, et al. Efficacy and tolerability of peginterferon alpha-2a with or without ribavirin in thalassaemia major patients with chronic hepatitis $C$ virus infection. BrJ Haematol. 2005;130(4):644-6.

8. Tabatabaei SV, Alavian SM, Keshvari M, Behnava B, Miri SM, Karimi Elizee P, et al. Low dose ribavirin for treatment of hepatitis $C$ virus infected thalassemia major patients; new indications for combination therapy. Hepat Mon. 2012;12(6):372-81.

9. Bacon BR, Shiffman ML, Mendes F, Ghalib R, Hassanein T, Morelli $\mathrm{G}$, et al. Retreating chronic hepatitis $\mathrm{C}$ with daily interferon alfacon-1/ribavirin after nonresponse to pegylated interferon/ribavirin: DIRECT results. Hepatology. 2009;49(6):1838-46.

10. Jacobson IM, Gonzalez SA, Ahmed F, Lebovics E, Min AD, Bodenheimer $\mathrm{HC}$, et al. A randomized trial of pegylated interferon alpha-2b plus ribavirin in the retreatment of chronic hepatitis C. The American journal of gastroenterology. 2005;100(11):2453-62.

11. Jensen DM, Marcellin P, Freilich B, Andreone P, Di Bisceglie A, Brandao-Mello CE, et al. Re-treatment of patients with chronic hepatitis $\mathrm{C}$ who do not respond to peginterferon-alpha2b: a randomized trial. Ann Intern Med. 2009;150(8):528-40.

12. Alavian SM, Tabatabaei SV, Behnava B, Mahboobi N. Optimal duration of treatment for HCV genotype 1 infection in slow responders: a meta-analysis. Hepat Mon. 2011;11(8):612-9.

13. Pearlman BL, Ehleben C, Saifee S. Treatment extension to 72 weeks of peginterferon and ribavirin in hepatitis c genotype 1-infected slow responders. Hepatology. 2007;46(6):1688-94.

14. Ide T, Hino T, Ogata K, Miyajima I, Kuwahara R, Kuhara K, et al. A randomized study of extended treatment with peginterferon alpha-2b plus ribavirin based on time to HCV RNA negative-status in patients with genotype $1 \mathrm{~b}$ chronic hepatitis C. Am J Gastroenterol. 2009;104(1):70-5.

15. Ferenci P, Laferl H, Scherzer TM, Maieron A, Hofer H, Stauber R, et al. Peginterferon alfa-2a/ribavirin for 48 or 72 weeks in hepatitis $C$ genotypes 1 and 4 patients with slow virologic response. Gastroenterology. 2010;138(2):503-1.

16. Andriulli A, Di Marco V, Margaglione M, Ippolito AM, Fattovich G, Smedile A, et al. Identification of naive HCV-1 patients with chronic hepatitis who may benefit from dual therapy with peginterferon and ribavirin. J Hepatol. 2014;60(1):16-21.

17. Van Vlierbergh H, Delanghe JR, De Vos M, Leroux-Roel G, Bas Steering Committee . Factors influencing ribavirin-induced hemolysis. J Hepatol. 2001;34(6):911-6.

18. Takaki S, Tsubota A, Hosaka T, Akuta N, Someya T, Kobayashi M, et al. Factors contributing to ribavirin dose reduction due to anemia during interferon alfa2b and ribavirin combination therapy for chronic hepatitis C.J Gastroenterol. 2004;39(7):668-73.

19. Telfer PT, Garson JA, Whitby K, Grant PR, Yardumian A, Hoffbrand $\mathrm{AV}$, et al. Combination therapy with interferon alpha and ribavirin for chronic hepatitis $C$ virus infection in thalassaemic patients. Br JHaematol. 1997;98(4):850-5.

20. Harmatz P, Jonas MM, Kwiatkowski JL, Wright EC, Fischer R, Vichinsky E, et al. Safety and efficacy of pegylated interferon alpha-2a and ribavirin for the treatment of hepatitis $C$ in patients with thalassemia. Haematologica. 2008;93(8):1247-51.

21. Huang CF, Huang JF, Yang JF, Hsieh MY, Lin ZY, Chen SC, et al. Interleukin-28B genetic variants in identification of hepatitis $C$ virus genotype 1 patients responding to 24 weeks peginterferon/ ribavirin. JHepatol. 2012;56(1):34-40.

22. Huang CF, Yeh ML, Huang JF, Yang JF, Hsieh MY, Lin ZY, et al. Host interleukin-28B genetic variants versus viral kinetics in determining responses to standard-of-care for Asians with hepatitis $C$ genotype 1. Antiviral Res. 2012;93(2):239-44.

23. Lin CY, Chen JY, Lin TN, Jeng WJ, Huang CH, Huang CW, et al. IL28B SNP rs12979860 is a critical predictor for on-treatment and sustained virologic response in patients with hepatitis $\mathrm{C}$ virus genotype-1 infection. PLOS ONE. 2011;6(3)

24. Ge D, Fellay J, Thompson AJ, Simon JS, Shianna KV, Urban TJ, et al. Genetic variation in IL28B predicts hepatitis C treatment-induced viral clearance. Nature. 2009;461(7262):399-401.

25. Di Marco V, Bronte F, Calvaruso V, Capra M, Borsellino Z, Maggio A, et al. IL28B polymorphisms influence stage of fibrosis and spontaneous or interferon-induced viral clearance in thalassemia patients with hepatitis $\mathrm{C}$ virus infection. Haematologica. 2012;97(5):679-86. 